\title{
Memórias cartaginesas: modernismo, Antiguidade clássica e a historiografia da Independência do Brasil na Amazônia, 1823-1923
}

\section{Carthaginian memories: modernism, Classic Antiquity and historiography of Brazil Independence in Amazon, 1823-1923}

\author{
Aldrin Moura de Figueiredo
}

Na noite do dia 16 de outubro de 1823 , um grupo de soldados do $2^{\circ}$ Regimento de Artilharia de Belém do Pará, juntamente com gente do povo, continuou uma série de ataques a estabelecimentos comerciais portugueses, iniciados na noite anterior. Os praças encarregados da guarda ficaram impedidos de esta-

\footnotetext{
Aldrin Moura de Figueiredo é professor do Programa de Pós-Graduação em História da Universidade Federal do Pará e pesquisador do CNPq (aldrinfigueiredo@uol.com.br).

Artigo recebido em 29 de dezembro de 2008 e aprovado para publicação em 4 de março de 2009.

Nota do autor: Versão ampliada e modificada de conferência apresentada no colóquio Os mortos do Brigue, realizado em Belém, no Palácio Antonio Lemos, sob o patrocínio da Câmara Municipal de Belém, em novembro de 2003. A pesquisa faz parte um projeto mais amplo sobre os círculos intelectuais na Amazônia entre 1888 e 1938, financiado pelo CNPq. Agradeço as leituras e sugestões de Benedito Nunes, Sidney Chalhoub, Magda Ricci e Stephen Barris a uma primeira versão do que vai aqui impresso, embora os equívocos porventura existentes sejam de minha inteira responsabilidade.
}

Estudos Históricos, Rio de Janeiro, vol. 22, nº 43, janeiro-junho de 2009, p. 176-195. 
belecer a ordem, tendo que recorrer à força naval vinda da Corte, sob o comando de John Pascoe Grenfell (1800-1869), que estava em Belém para impor a "adesão" do Pará ao novo Império do Brasil. Grenfell determinou, já alta noite, o desembarque de tropas, reforçadas por elementos dos navios mercantes, que detiveram todas as pessoas encontradas pelas ruas e casas suspeitas e denunciadas. No dia 17 foram fuzilados cinco indivíduos. Os soldados, inclusive os cidadãos detidos na noite anterior, em número de 256 , foram recolhidos à cadeia pública até o dia 20, quando foram transferidos para bordo de um brigue, denominado São Fosé Diligente, depois Palhaço, sob o comando do primeiro-tenente Joaquim Lúcio de Araújo.

Os presos foram confinados no porão da embarcação, num pequeno espaço de 30 palmos de comprimento, 20 de largura e 12 de altura, com as escotilhas fechadas e apenas uma pequena fresta aberta para a entrada do ar. Gritos, reclamações, súplicas e ameaças foram ouvidos durante a noite. Da narrativa dos sobreviventes, depreende-se que, tendo sido lançada água do rio aos prisioneiros numa tina existente no porão, agravou-se o tumulto. A guarnição, decidida a acalmar os ânimos, disparou alguns tiros para o interior do porão, onde se espalhou grande quantidade de cal, fechando a abertura do porão. No dia seguinte, às sete horas da manhã, aberto o porão do navio na presença de seu comandante, contaram-se 252 corpos, com sinais de longa agonia. Apenas quatro sobreviventes foram resgatados, dos quais, no dia seguinte, apenas um, por alcunha João Tapuia, resistiu. Grenfell não assumiu a culpa pelo incidente, argumentando que o ataque não fora executado sob suas ordens. ${ }^{1}$

Esse fato marcou gerações de intelectuais paraenses e, obviamente, em 1923, foi relembrado numa disputa sem precedentes sobre a entronização dos heróis e dos vilões, dos vencedores e dos derrotados. Como num jogo da memória, a tragédia do brigue Palhaço, como ficou conhecida desde o século XIX, passou ao presente numa analogia com uma outra tragédia aparentemente perdida no tempo. As lembranças dos historiadores e políticos paraenses revisitavam uma série de três guerras que opuseram a República Romana e a República de Cartago, cidade-estado fundada por fenícios africanos, que os romanos chamavam de poeni - derivação de Poenici -, daí o termo púnicas. Depois das guerras, severa foi a pena imposta a Cartago, que teve de pagar pesados impostos e também ficava proibida de fazer guerra a outros povos sem ordens do senado romano. Em Roma, o senador Catão iniciava intensa campanha contra Cartago. Todos os seus discursos terminavam com a frase: "Cartago precisa ser destruída" (delenda est Carthago). Usado o pretexto de que Cartago desobedecera a Roma, em 146 a.C, Cipião Emiliano, com suas forças, arrasou totalmente a cidade, queimando-a e colocando sal pelo solo, "para que ali nada mais crescesse" (Loreto, 2007). 
A história da destruição de Cartago virou mito. Paradigma heurístico para a história das civilizações modernas, o uso do mito político da guerra entre Roma e Cartago estava na ordem do dia. Nos debates políticos em torno das comemorações do centenário do episódio do brigue Palhaço, em 1923, a analogia com a história de Cartago veio à tona novamente. Isso ficou mais evidente nas reuniões do Instituto Histórico e Geográfico do Pará e nas contendas entre o historiador João de Palma Muniz (1873-1927), que um ano antes lançava sua tese sobre a adesão do Pará à Independência do Brasil, e o jurista Augusto Meira (1873-1964), professor emérito da Faculdade de Direito do Pará, deputado na Assembleia Estadual e célebre militante na seara das letras locais. ${ }^{2}$ No entanto, a diversidade das interpretações da "adesão" ou da "guerra" de Independência representaram mais do que uma pendenga historiográfica. Houve mesmo uma mudança no eixo interpretativo da história da Amazônia no contexto do modernismo local. Porém, antes de qualquer coisa, a efeméride e sua comemoração revelaram muito sobre aquilo que viríamos, pouco a pouco, chamar de uma nova interpretação da identidade amazônica.

A ideia estava no ar. No mesmo ano de 1923, Joseph Ward Swain comentou os usos que Theodor Mommsen (1817-1903) fizera de seu conhecimento da Antiguidade latina para comparar as relações entre Inglaterra e Alemanha no século XIX, em analogia ao poderio "naval e militar" cartaginês e à força "militar e continental" romana. ${ }^{3}$ Um ano antes, o poeta inglês T. S. Elliot publicava o seu The West Land, recuperando a ideia de terra arrasada no mesmo momento em que o termo "paz cartaginesa" era solidificado no contexto do pós-guerra. Lembre-se que em 1919 o Tratado de Versalhes, com uma representação de 32 países aliados ou neutros -, impôs essa paz "severa" à Alemanha. ${ }^{4}$ Paz cartaginesa foi expressão cunhada por John Maynard Keynes (1883-1946) no livro The economic consequences of the peace, de 1919, para denunciar a emergência da paz a partir da completa destruição do "inimigo", com a esterilização da terra na qual ele vive, em alusão ao sal jogado sobre as terras de Cartago pelos romanos no final da Terceira Guerra Púnica. ${ }^{5}$ Está claro, portanto, que o uso político da história da Antiguidade pelos intelectuais da Amazônia na década de 1920 fazia parte, na verdade, do repertório cognitivo e analítico da época.

Uma geração de modernistas paraenses tomou a si a tarefa de reescrever essas histórias, recompor efemérides e dar novo sentido à identidade amazônica. O discurso competente sobre as festas da pátria, no entanto, ainda pertencia aos velhos, por isso mesmo renovação literária foi assunto para depois. Por enquanto, é hora de demonstrar como as festas do centenário da Independência do Brasil foram essenciais para configurar publicamente os debates produzidos no interior desse movimento intelectual. Em vista disso, é necessário não se restringir apenas às exterioridades e à superfície dos significados das festas cívicas, para 
que se possam entender os contornos mais gerais das mudanças que estavam em pleno curso. A própria emergência histórica de um léxico datado, como nos conceitos independência, adesão, emancipação política, libertação, vida livre, deve ser encarada como um indício concreto para situar nossos personagens, imersos que estavam numa problemática política e cultural central naquele contexto histórico. Nesse processo de lapidação das interpretações sobre nossas origens nacionais, o Instituto Histórico e Geográfico do Pará teve, como já era de se esperar, uma lida das mais destacadas - sendo mesmo o principal responsável pelo tom, quase uníssono, que então ecoou na imprensa, embora não fosse o único. A questão-chave para o sodalício era a de tentar, a todo custo, apagar das memórias as versões de que teria existido uma guerra de independência (Figueiredo, 1908).

Os dois nomes centrais nessa formulação foram o do jurista Candido Costa e o do engenheiro João de Palma Muniz, ambos figuras de proa do Instituto. O primeiro era um apaixonado por compêndios e polianteias cívicas, já tendo em seu currículo a organização de volumes especiais sobre o $4^{\circ}$ centenário do Descobrimento da América e do Brasil, o jubileu da Guerra do Paraguai, e já começando os trabalhos para o Livro do Centenário (Costa, 1900; 1919; 1924). O segundo já era um reconhecido pesquisador, qualificado também como "escritor técnico". ${ }^{6}$ Desde a primeira década do século XX, Palma Muniz vinha realizando trabalhos de pesquisa sobre as delimitações municipais do Pará, assim como índices dos registros de terra e sesmarias da Amazônia e inúmeras monografias sobre as municipalidades paraenses. Era, por isso mesmo, um profundo conhecedor da documentação disponível nos arquivos brasileiros e estrangeiros sobre o Norte do Brasil. No início dos anos 1920, seria o autor das teses mais polêmicas sobre a Independência do Brasil no Pará.

A palavra tese era, naquela situação, também um termo emblemático. Assinale-se que, além da novidade do evento comemorativo, a própria agremiação acenava com mudanças em sua diretoria, concorrendo para a valorização daquela que pretendia ser uma nova leitura das origens nacionais. A nova diretoria do Instituto Histórico do Pará, empossada em março de 1923, apesar de muito afinada com a anterior, deu chance para que outros nomes se colocassem em evidência. $O$ palco principal de exposição dessas novas versões da história do Brasil, sob o ângulo paraense, foi primeiramente a sessão solene organizada pelo IHGP em 7 de setembro de 1922, incluída pelo governador do estado, Dr. Souza Castro, no programa oficial dos festejos. Por proposta de Palma Muniz, primeiro secretário e membro da comissão de redação da revista do Instituto, foi aprovado que a próxima revista da instituição seria constituída com 30 teses "referentes ao movimento de adesão do Pará à Independência" (Lobo; Muniz; Campos, 1922: II). 


\section{Propostas de teses referentes ao movimento de adesão do Pará à Independência do Brasil}

\begin{tabular}{ll}
\hline I & O 14 de abril de 1823 em Belém e suas consequências \\
\hline II & O 28 de maio de 1823 em Muaná \\
\hline III & A adesão do Grão-Pará à Independência \\
\hline V & A ação de Patroni na Independência \\
\hline VI & A adesão do município de Belém à Independência \\
\hline VII & A adesão do município de Bragança à Independência \\
\hline VIII & A adesão do município de Cametá à Independência \\
\hline IX & A adesão do município de Chaves à Independência \\
\hline X & A adesão do município de Curuçá à Independência \\
\hline XI & A adesão do município de Macapá à Independência \\
\hline XII & A adesão do município de Maracanã à Independência \\
\hline XIII & A adesão do município de Óbidos à Independência \\
\hline XIV & A adesão do município de Santarém à Independência \\
\hline XV & A adesão do município de Vigia à Independência \\
\hline XVI & A interferência da imprensa na Independência \\
\hline XVII & A ação do cônego Batista Campos na Independência \\
\hline XVIII & O papel de Grenfell na Independência \\
\hline XIX & A interferência militar pró e contra a Independência \\
\hline XX & O clero e a Independência \\
\hline XXI & Manifestações de nativismo e seus efeitos antes e depois da Independência \\
\hline XXII & O estudo social do Grão-Pará na época da Independência \\
\hline XXIII & Biografias de homens que interferiram nos acontecimentos da Independência \\
\hline XXIV & Relações do governo do Grão-Pará com as metrópoles portuguesa e brasileira nas lutas pela adesão \\
\hline XXV & Organização administrativa da Província do Pará após a Independência \\
\hline XXVI & Estado dos conhecimentos geográficos e estatísticos da Província do Pará na época da adesão \\
\hline XXVII & A ação dos deputados paraenses nas Cortes Gerais de 1821 \\
\hline XXVIII & O estado intelectual do Pará na época da Independência \\
\hline XXIX & Interferência da maçonaria na adesão do Pará à Independência \\
\hline XXX & Assistência aos doentes e desamparados na época da Independência \\
\hline & Causas que influíram para o retardamento da adesão do Pará à Independência \\
\hline
\end{tabular}

Fonte: Atas do IHGP, sessão de 7 de setembro de 1922.

De fato, foi exatamente Palma Muniz o herói-fundador dessa interpretação que, ainda hoje, campeia livre na maior parte dos estudos sobre o 
tema e suas mediações pela historiografia paraense. A principal tarefa desempenhada por esse historiador foi a de reescrever e acomodar a ação dos personagens envolvidos nas tramas da Independência, de tal modo que a história das lutas contrárias à formação da nacionalidade brasileira se transformasse exatamente no oposto. A nação seria representada por lutas pela adesão à Corte do Rio de Janeiro e ao Império do Brasil. A primeira ideia era a de que tanto os próprios membros do Instituto como outros interessados de fora pudessem apresentar seus trabalhos, obviamente dentro da linha proposta pela comissão da revista.

No entanto, não houve uma resposta afirmativa para todas as teses, das quais apenas seis foram apresentadas, a maior parte com consórcios da casa. O resultado do colóquio provou que essa tese praticamente resultava de um esforço pessoal de Palma Muniz. O primeiro passo foi o de revisar a historiografia clássica, produzida no século XIX, especialmente por Antonio Ladislau Monteiro Baena (1781-1851), Francisco Adolfo Varnhagen (1816-1878) e Domingos Antônio Raiol (1830-1913), todos ligados ao Instituto Histórico e Geográfico Brasileiro. Enquanto esses autores definiam o processo de Independência como a própria formação do Império brasileiro, sob a linhagem da família real portuguesa, Palma Muniz propunha uma versão civil dessa história, assentada numa nacionalidade popular. Em outras palavras, a figura do "súdito" da historiografia romântica deu lugar ao "povo" na versão dos modernos dos anos 1920. O ideário da nação não passaria mais pela constituição de um país branco e europeizado, e ao invés de um Estado suficientemente forte e centralizado, a ênfase recaía agora sobre a noção federativa e republicana.

Teses apresentadas sobre o movimento de adesão do Pará à Independência do Brasil

\begin{tabular}{lll}
\hline III & A adesão do Grão-Pará à Independência & João de Palma Muniz \\
\hline VI & A adesão do município de Bragança à Independência & Augusto Corrêa \\
\hline XI & A adesão do município de Maracanã à Independência & João de Palma Muniz \\
\hline XII & $\begin{array}{l}\text { Apontamentos biográficos de alguns vultos que figuraram } \\
\text { no período de 1821 a 1823 }\end{array}$ & João de Palma Muniz \\
\hline XVIII & A interferência militar pró e contra a Independência & Luiz Lobo \\
\hline XIX & O clero e a Independência & Ricardo Rocha \\
\hline nova & Em marcha para a Independência & Manuel Braga Ribeiro \\
\hline
\end{tabular}

Fonte: Revista do IHGP, vol. 4, n. 4, 1922. 
Tópicos desenvolvidos na $3^{\text {a }}$ tese

“Adesão do Grão-Pará à Independência”, por João de Palma Muniz

\begin{tabular}{ll}
\hline I & Repressões militaristas ao sentimento nacional \\
\hline II & As malogradas insurreições de 14 de abril e 28 de maio de 1822 \\
\hline III & Ação primária da Junta Revolucionária \\
\hline IV & Primeiras efervescências nativistas e eleição dos deputados às Cortes \\
\hline V & Os primeiros pioneiros das ideias de Independência \\
\hline VI & Advento da imprensa no Grão-Pará e sua ação na adesão à Independência \\
\hline VII & Sucessos do ano de 1822 no Grão-Pará \\
\hline VIII & Acontecimentos externos ligados aos sucessos do Grão-Pará \\
\hline IX & \\
\hline X & \\
\hline XI & A Província do Grão-Pará nos fins da Dominação portuguesa \\
\hline XII & Adere a Província do Pará à Independência completando a pátria brasileira \\
\hline XIII & A Independência nos municípios do interior \\
\hline
\end{tabular}

Fonte: Revista do IHGP, vol. 4, n. 4, 1922.

Apesar de ter consciência de estar tratando de um assunto polêmico, tenso e excessivamente ambíguo, Palma Muniz apostava no tom conciliador que o conceito de adesão traria para o ânimo de sua geração em ressignificar a identidade nacional, dialogando com o regional. Por isso mesmo, sua leitura procurou endossar certa projeção do Pará para a trajetória do novo país que iria nascer. Nesse ponto distante do Reino Unido, teriam chegado pela primeira vez, ainda em 1820, as notícias da Revolução Constitucionalista que, no ano anterior, abalou fortemente o absolutismo português. O primeiro herói da versão de Palma Muniz era justamente o mensageiro dessas notícias - Felippe Patroni (1794-1866), sujeito que pretendia fazer sua terra aderir ao movimento do Porto, "esboçando a gênese da revolução" no Grão-Pará. ${ }^{7}$ A partir daí, e a cada passo dessa história, começavam a reaparecer todos aqueles nomes entronizados numa galeria histórica dos maiores vultos do Pará, que Palma Muniz e seus confrades expuseram no Teatro da Paz em 1918 (Figueiredo, 2003). Passava-se então para o ponto seguinte em sua tese central: o árduo trabalho de Patroni conseguiu até mesmo depor a Junta Governativa, aclamando uma outra, sob a presidência do Vigário da Sé, Romualdo de Seixas - outro herói no panteão da Independência. Por obra dessa junta, teria havido o reconhecimento definitivo do "movimento revolucionário na Província", à custa da consolidação da "autoridade" de seu governo e, principalmente, da garantia dos "direitos públicos" dos cidadãos $(\mathrm{Mu}-$ 
niz, 1922: 39). Como desdobramento, foram enviados emissários aos pontos mais importantes do interior do Pará, ao Rio de Janeiro e a Lisboa. Nessa leva, Patroni foi para Portugal a fim de tomar pé da situação. Por lá, o rapaz ficaria convencido de que sua terra era apenas uma porção do Reino, sem representatividade e reconhecimento na Corte. Surgia então, pela primeira vez, a reação nativista quando, em novembro de 1821, Patroni se dirigiu ao rei, em tom enérgico, acusando-o de absolutista:

Os povos não são bestas que sofrem em silêncio todo o peso que lhes impõe. O Brasil quer estar ligado a Portugal; mas se o ministério do Reino-Unido, pela frouxidão, contribuir para a consistência e duração da antiga tirania, o Brasil em pouco tempo proclamará sua Independência. (Muniz, 1922: 74)

A recuperação que Palma Muniz fez da fala de Patroni diante do rei abriria o caminho para os próximos passos rumo à Independência. Primeiro a consciência de alguns brasileiros, como Patroni, da dura submissão colonial (Muniz, 1922: 95-117) e, consequentemente, do nascimento de uma revolução forjada no interior das primeiras tipografias, pela propaganda separatista (Muniz, 1922: 118-132). Se em 1821 Patroni já havia feito circular uma Gazeta do Pará, comparando a realidade local com a vida na Corte, denunciando os desvios das rendas públicas e defendendo a Constituição como o único instrumento capaz de reordenar as relações da coroa com a sociedade civil, em 1822, com o jornal $O$ Paraense, Patroni fundaria de vez a nacionalidade brasileira, vista sob o ângulo do Norte (Muniz, 1922: 133-168). Isto tanto seria verdade que, no entender de Palma $\mathrm{Mu}$ niz, justamente na chefia dessa folha estava o próximo herói da lista - o cônego Batista Campos. A resposta dos portugueses não tardou e, em março de 1823, foi destituída a Junta de Governo, e todos os ativistas foram deportados para longe de Belém. A prova de que a nacionalidade brasileira estava nascendo viria, para o nosso intérprete, exatamente pelas mãos da repressão. Por isso mesmo, sob o comando dos adversários, $O$ Paraense foi rebatizado como Luso-Paraense, transformando-se em arauto da dominação portuguesa (Muniz, 1922: 169-189; 190-223). Apesar de toda essa perseguição contra os nacionais, o autor fez emergir nessa história o "sentimento nacional" que, segundo ele, se alastrava com força entre os que ansiavam por liberdade. $\mathrm{O}$ momento mágico dessa reação dos paraenses poderia ter acontecido no intervalo de apenas cinco meses. A apropriação dessas histórias por Palma Muniz é um capítulo à parte na criação das legendas da Independência e do movimento cabano de 1835 . O primeiro capítulo teria ocorrido na madrugada de 13 para 14 de abril de 1823, quando um grupo de brasileiros fez rebentar uma 
"insurreição" por liberdade, tomando o quartel e o parque de artilharia da capital do Pará. Porém, como o $3^{\circ}$ Regimento de Infantaria não "aderiu" à luta, os portugueses tripudiaram sobre os vencidos. Nada menos do que 270 brasileiros foram condenados à morte, sendo o próprio cônego João Batista Gonçalves Campos (1782-1834) colocado na boca de um canhão. Mais uma vez, em meio à história, aparecia o próximo herói da lista, o bispo do Pará, D. Romualdo de Sousa Coelho (1762-1841), que conseguiu salvá-los da morte, convencendo os portugueses que os mandassem para serem julgados em Lisboa (Barata, 1973: 200-211).

Já em Portugal, acabaram alcançando a anistia por intermédio do conde de Vila Flor, que conhecia muitos dos prisioneiros, pois havia sido governador e capitão-general do Pará, de 1817 até 1820 . Os portugueses afinal tinham vencido essa parte da guerra. O outro capítulo da legenda teria começado em 10 de agosto, com a chegada do brigue de guerra Maranhão, sob comando do capitão-tenente inglês John Pascoe Grenfell. A tarefa do sujeito teria sido a de executar um plano traçado por seu superior, o lord Thomas Alexander Cochrane (1775-1860), chefe de uma esquadra organizada por Pedro I, que a essa altura já era imperador do vizinho Brasil, desde o ano anterior. Segundo Palma Muniz, a ideia do monarca brasileiro era a de fazer o Grão-Pará "aderir" ao Império do Brasil. Com o navio ancorado na baía do Guajará, defronte a Belém, Grenfell teria convencido a Junta Governativa a proclamar a Independência em 15 de agosto de 1823, blefando sobre uma esquadra imaginária que estaria vindo ao assalto da cidade (Muniz, 1922: 224-288). Neste ponto, a tese de Palma Muniz encontrou vigorosos opositores entre os confrades do próprio Instituto. Enquanto o historiador prosseguia explicando que os oficiais ingleses, que serviram à marinha brasileira, foram grandes estrategistas, diplomatas e mentores da pacificação, a maioria dos intelectuais da casa, de correntes políticas as mais diversas, não aceitava o heroísmo dos ingleses. Theodoro Braga, alguns anos depois, resumiu, de maneira clara, os limites da peleja: "Foi doloroso que uma sagrada ideia nacional, unindo todos os corações de brasileiros, no único desejo natural e evolutivo de liberdade ampla para um grande país como o nosso, fosse imposta e levada a efeito por estrangeiros mercenários e sanguinários" (Braga, 1931: 106-7). Mas é importante referir que, além das muitas tensões encerradas na legenda da emancipação paraense, havia uma imagem que centralizou o campo das disputas em toda essa história, gerando uma das principais rixas na atuação política dos modernistas locais.

O fato envolvia novamente os nomes dos marinheiros ingleses, sempre na ponta da discórdia entre os literatos. A questão era que, mesmo depois de proclamada a Independência, os conflitos entre brasileiros e portugueses pareciam longe do fim. Como desdobramento do acontecido em 15 agosto, a revolta da soldadesca local foi patente. Controlado mais esse levante, Grenfell teria ordenado, com enorme "brutalidade", o fuzilamento de cinco dos soldados envolvidos, bem defron- 
te ao largo do Palácio do Governo. Sem muitas cerimônias, "fez meter no porão do brigue Diligente" os outros 256 participantes da rebelião. Theodoro Braga assim descrevia o final dessa história: "Fechados no porão daquele navio, não tardaram 255 infelizes patriotas brasileiros a sucumbir, sendo enterrados depois no sítio Penacova, não longe de Belém”. A tragédia desse navio, depois chamado de brigue Palhaço, marcou profundamente, para os contrários de Palma Muniz, o significado da Independência no Pará: "Esse lúgubre acontecimento, lúgubre e inútil, friamente concebido e executado pelo preposto inglês, teve lugar no dia 17 de outubro de 1823, cinco dias depois de ter sido aclamado imperador do Brasil independente, a 12 desse mês, dia de seu aniversário natalício, aclamação feita com toda a solenidade determinada pela Junta Provisória do Governo da Província" (Braga, 1931: 107). Com esse episódio terminava a exposição do essencial na tese desenvolvida por Palma Muniz e, com o registro de Theodoro Braga, a apresentação da entonação opositora. Com efeito, não era apenas o seu amigo pintor que tinha discordância em relação ao seu ponto de vista - e isso ficou claro, durante a comemoração do 15 de agosto, naquele ano de 1923.

Numa sessão no próprio Instituto Histórico, foi apresentada a polianteia intitulada 15 de agosto de 1823: a adhesão do Pará à Independencia, 1823-1923, publicada em alusão à data da Proclamação da Independência no Pará. Para a nossa sorte, o evento foi minuciosamente registrado pelo já citado Candido Costa, nas suas anotações sobre os festejos de 1922-1923. Mais do que a publicação em si, nos interessa aqui analisar a polêmica em torno das teses de Palma Muniz, em que o sentido-mor do conceito de "adesão" estava impresso já no título do livro. Participaram da obra alguns dos mais eminentes intelectuais da época, tratando do assunto, segundo seu interesse e especialidade, fosse ensaio ou tese, em prosa ou em verso. Estavam lá alguns dos nomes mais importantes da intelectualidade paraense, como o crítico Eustachio de Azevedo e os engenheiros-historiadores Ignacio Moura, Palma Muniz, Henrique Santa Rosa. Em meio à variedade temática do volume, a história teve, como já era de se esperar, um lugar destacado - e o ponto de maior enfoque foi o da Independência do Brasil, sob a ótica da controversa mortandade no brigue. A tese de Palma Muniz recuperava a biografia Grenfell, desde quando este, em 1811, aos onze anos, ingressara na Companhia Britânica das Índias Orientais, a serviço da qual fizera diversas viagens à Índia. Logo a seguir, explicava a trajetória de Grenfell, a partir de 1819, quando passou a servir sob as ordens de Thomas Cochrane, participando das lutas da Guerra de Independência do Chile, transformando-se em vitorioso, apesar de ter sido gravemente ferido nos conflitos. Três anos depois, viria ao Maranhão e ao Pará, já no posto de comandante, juntamente com outros oficiais e soldados europeus, para tomar parte nas lutas da Guerra da Independência do Brasil. Palma Muniz teria que recontar todos os momentos quentes da história: a adesão do Pará, a atribula- 
da história que incluiu o fuzilamento de cinco paraenses no Largo do Palácio, em 17 de outubro de 1823, o episódio do Cônego Batista Campos e, por fim, a tragédia do brigue Palhaço, onde foram vitimados 256 prisioneiros, detidos no porão daquela embarcação no porto de Belém. Havia também pecha de fujão pairando sobre a figura do pretenso herói. ${ }^{8}$

A questão é que, em 1824, Grenfell deixara o Pará, embora houvesse ordem de prisão contra ele. E mais: já na Corte, como muita habilidade, voltou a oferecer mais uma vez os seus serviços ao Imperador. Desta feita para combater os revoltosos republicanos da Confederação do Equador, em Pernambuco. ${ }^{9}$ Após derrotá-los, retornou ao Rio de Janeiro, onde, julgado em Conselho de Guerra, foi absolvido de seus crimes. Depois com o Comandante James Norton (1789-1935) serviria na Guerra Cisplatina em 1826, participando de combates em Buenos Aires, onde viera a perder o seu braço direito. ${ }^{10}$ Após um retorno à Inglaterra para restabelecer a sua saúde, voltou ao Brasil em 1828 e, no ano seguinte, já iria para Montevidéu onde casaria com Maria Dolores Masini, com quem teve vários filhos. Sua carreira de lutas, no entanto, não pararia por aí. Durante o Período Regencial foi destacado, em 1836, para reprimir a Revolução Farroupilha, no sul do país. Nomeado comandante das forças navais estacionadas no Rio Grande do Sul, comandou a esquadra imperial na Batalha do Fanfa, à frente de 18 navios de guerra, escunas e canhoneiras. A esquadra bloqueou o lado sul da ilha enquanto as tropas sob o comando de Bento Manuel Ribeiro (1783-1855) fechavam o cerco por terra. Ao final da batalha renderam-se ou foram capturadas várias importantes lideranças farroupilhas: Bento Gonçalves, Tito Lívio Zambeccari, Pedro Boticário, José de Almeida Corte Real, José Calvet, entre outros. ${ }^{11}$ Isso não era tudo: em 1841, Grenfell seria nomeado vice-almirante e, em 1846, cônsul geral do Brasil em Liverpool. A atividade diplomática jamais o afastaria da experiência das guerras. Retornou ao Brasil quando da Guerra contra Manuel Oribe e Juan Manuel Rosas (1850-1852), nomeado comandante-em-chefe das forças navais brasileiras na bacia do rio da Prata, destacando-se na Passagem de Tonelero. Com o fim da guerra, retornou a Londres a fim de reassumir as funções de cônsul na Inglaterra, onde veio a falecer aos 69 anos.

Biografia similar era a de Thomas Cochrane. Ainda jovem, havia combatido nas Guerras contra Napoleão Bonaparte, tendo demonstrado tanta ousadia em suas operações navais que o próprio imperador francês o teria apelidado de Loup de Mer (lobo do mar). Paralelamente à sua carreira naval foi eleito membro do Parlamento. A entrada nos liames da Câmara lhe traria muitos problemas. Em 1814, foi condenado à prisão por haver realizado supostas atividades fraudulentas, vendo-se inclusive obrigado a abandonar a carreira naval. As lutas no ultramar foram uma saída mais honrosa. Em maio de 1817, fora contratado pelas forças independentistas chileno-argentinas para que comandasse a esqua- 
dra que tinha por missão eliminar o poder local assentado no Vice-reinado do Peru, sendo sua contribuição decisiva na guerra, colaborando com os generais Bernardo O’Higgins Riquelme (1778-1842) e José de San Martín (1778-1850). ${ }^{12}$ Tomou parte nas lutas da Independência na Bahia e do Maranhão em 1823, e foi feito, pelo imperador D. Pedro I, marquês do Maranhão. Entre 1821 e 1825, Cochrane ajudou os independentistas brasileiros, lutando contra a frota naval lusitana. Também combateu em Pernambuco, com Grenfell, em 1824, na Confederação do Equador. Depois da vitória, tentou inutilmente receber pagamento do governo imperial pelos serviços e, como não foi atendido, levou alguns navios como indenização. Após finalizar sua participação no Brasil, dois anos mais tarde atuou na guerra de Independência da Grécia (1827-1828), enfrentando os navios do Império Otomano. O regresso ao Reino Unido se deu em 1830 e, no ano seguinte, enfrentou a morte do pai, tornando-se o Décimo Conde de Dundonald. O status restabelecido serviu para sua readmissão na Armada britânica, em 1832, onde chegou a alcançar a patente de almirante. Morreu em Londres em 1860 aos 85 anos (Vale, 2004; 2008; Cordingly, 2007).

O brilho biográfico de Grenfell e Cochrane não chegou a comover muitos dos intelectuais do Instituto Histórico do Pará. Contrapondo-se à versão de Palma Muniz, levantou-se o jurista Dr. Augusto Meira, "acérrimo gladiador na arena jornalista contra o $2^{\circ}$ tenente Grenfell”, a quem atribuía "as cenas vandálicas do Palhaço, onde pagaram com a vida tantos mártires". Segundo Candido Costa, "foi esse um assunto interessante, que prendeu bastante a atenção pública", especialmente quando os Srs. Palma Muniz e Henrique Santa Rosa rebateram em "contraditas opostas". A matéria era tão candente que o próprio Candido Costa colocou-se ao lado das teses do secretário do Instituto, afirmando que este conseguira provar, "com bons argumentos e conceitos emitidos por eméritos historiadores, a sem razão dos apodos assacados contra Grenfell" (Costa, 1924: 138). Entrou na briga o advogado e jornalista José Carvalho, também membro do Instituto, "brandindo armas de defesa" a favor de Palma Muniz, afirmando que o comandante inglês "devia merecer dos contemporâneos e dos pósteros os maiores aplausos de reconhecimento, como o principal fator da emancipação política do Pará”. Mas, apoiado por Mecenas Rocha e Henrique Jorge Hurley, o Dr. Augusto Meira "não cedeu um ceitil do propósito em que se manteve, pois aferrado à sua lógica e às suas ideias", parecia cada vez mais firme em seu enredo. A imagem mais forte bradada na sala do Instituto foi a de que Grenfell teria mesmo sido "o responsável pela hecatombe do brigue Palhaço, sendo ele a sua delenda Carthago". ${ }^{13}$ Mais que uma luta retórica e exercício de erudição no campo da história, o que se viu foi de fato um uso político da história e seus significados no presente. ${ }^{14}$ Numa alusão a Pierre Ansart, penso que estava em jogo, entre os intelectuais paraenses, uma longa história de ressentimentos (Ansart, 2004: 15-34). 
Aos olhos de Augusto Meira, a imagem de Cartago destruída somava-se à imagem do algoz romano. John Grenfell seria comparável ao espírito do general romano Públio Cornélio Cipião Emiliano, também chamado Segundo Africano e Numantino (184-129 a.C.). A história, como mestra da vida, narrava e ensinava isso ao presente. Cipião Emiliano foi considerado um notável estrategista em seu tempo. Conhecedor da cultura clássica grega e grande orador, somando a isso o desempenho e destaque na luta contra Cartago, além de ter sido o responsável pela implantação do poder romano na península Ibérica. Adotado pela nobre família Cornélia, influente nos mais altos círculos do poder, e orientado pelo historiador grego Políbio (203-120 a.C.) e pelo filósofo Panécio de Rodes (185-100 a.C.), adotou a carreira militar e, depois de exercer o cargo de tribuno na Hispânia, foi para a África a fim de lutar contra os cartagineses na Terceira Guerra Púnica. Mas se as matrizes da interpretação de Palma Muniz já estão perfeitamente esclarecidas ao leitor, ainda são necessárias maiores explicações para as origens das leituras de seus oponentes. Em primeiro lugar, vale ressaltar que foi exatamente por esse quadrante que emergiu a principal vertente do nativismo modernista no Pará, e, diferentemente do que aconteceu com as teses de Palma Muniz, os seus debatedores formularam seus conceitos produzindo e cotejando estudos etnológicos, folclóricos, históricos, jurídicos e literários.

Assim como a legenda de Cartago foi ficcionalizada inúmeras vezes, também a história da resistência do caboclo amazônico e do índio amazônico ao jugo colonizador na Colônia e no Império haveria de ser teatralizada, musicada e romanceada. ${ }^{15}$ Lembre-se que, ainda no século XIX, Gustave Flaubert (1821-1880), por volta de 1857, começou a planejar o romance Cartago. Viajou até a África, visitando as ruínas da cidade, leu em torno de 100 volumes para embeber-se no tema - obras de história, arte militar, patologia e religião. Em suas cartas, registrou o sofrimento que era dedicar-se à realização desse livro. Salambô, como acabou por intitular-se o romance histórico sobre Cartago, é uma obra impressionante, com imensa descrição de ambientes, vestimentas, objetos, costumes, e páginas descrevendo batalhas com detalhes de crueza (Flaubert, 1990; 2001; Blossom, 1915; Reid, 1995; Gagnebin, 1992; Dürr, 2002; Lorinszky, 2002). Não somente esse livro, mas principalmente a escrita de seu autor, se tornou um modelo de "belas letras" para o ocidente culto dos fins do século XIX (Clément, 1999; Bouillaguet, 2000; Chardin, 2000), como podem comprovar as próprias obras, referências e citações de autores paraenses da época. Com Augusto Meira e Jorge Hurley não seria diferente. Uma prova disto foram os muitos comentários na imprensa paraense sobre a tradução feita em Lisboa por João Barreira do romance de Flaubert (Flaubert, 1905; Meira, 1906a: 2). O tema do romance histórico vinha à cena para a educação dos sentimentos do presente. $\mathrm{O}$ próprio Augusto Meira lembrara das polêmicas em França, entre Sainte-Beuve (1804-1869) e Flaubert, numa série de acusações de imprecisões históricas em 
Salambô, como a crucifixão de leões, a descrição do templo de Tanit, o uso de perfumes pela filha de Amílcar, entre outras tantas que o autor houve por rebater. Também lembrou da resposta dura de Flaubert a outro crítico, Guillaume Froehner, acusado publicamente de leviano. ${ }^{16}$

Com Jorge Hurley esse universo entre a história, a literatura, a política e a reconstrução de uma memória mítica da Amazônia se ampliaria muito mais. $\mathrm{Na}$ década seguinte aos debates em torno da Independência do Brasil no Pará, Hurley foi, sem nenhuma dúvida, o intelectual mais prolífico. Advogado, cultor das letras, dublê de poeta, e depois juiz de direito, Hurley desde a década de 1910 esteve envolvido diretamente em processos de pacificação de índios na região do rio Gurupi, na divisa do Pará com o Maranhão (Figueiredo, 2008). A partir dessa experiência e de vários estudos na comissão de etnologia do IHGP, tomou para si a interpretação de que a tragédia do brigue Palhaço, muito além de um evento apenas relacionado à Independência, foi, mais do que tudo, o embrião do levante cabano de 1835 e 1836, expresso no ódio que nativos do Pará guardaram em relação às autoridades portuguesas. Associando-se a outros autores (Meira, 1908; 1913; Rocha, 1907; 1908; e Braga, 1915a; 1915b; 1916; 1917; 1919; 1920), Hurley construiu, nos anos seguintes, uma polêmica sem precedentes com a obra de Palma Muniz, especialmente a partir do ensaio biográfico sobre Grenfell, que este publicou em 1926 (Muniz, 1926). Durante toda a década de 1920, Hurley realizou uma pesquisa monumental com a documentação do Arquivo Público do Pará, para provar que os "traços cabanos" resultavam da "indignação e revolta" que se espalhou por todo o interior do Pará, gestada no íntimo dos índios e tapuios paraenses. Nesse contexto, "Grenfell transformara-se, de embaixador da Independência do Brasil, em carrasco dos paraenses", provando a todos ter sido "um simples mercenário". ${ }^{17}$ A tese de Hurley, divulgada não apenas em estudos históricos mas também em ensaios literários, poesia e folclore (Hurley, 1920; 1928; 1931a; 1931b; 1932a; 1932b; 1934; 1938), ajudou a imprimir entre os modernistas uma outra leitura do conceito de adesão (Figueiredo, 2001; Ricci, 2007). Se todos já tinham claro que a independência política também significava independência literária, agora a adesão ao Império do Brasil também foi reinventada como adesão ao modernismo brasileiro e paulista, numa alusão à Semana de Arte Moderna de 1922. E mais do que isto: se a história do antigo GrãoPará teria sido forjada à distância da trajetória brasileira, o mesmo teria ocorrido no âmbito da literatura. E, se na década de 1820 o Grão-Pará se aproximou do Brasil, aderindo a um novo projeto de nação, na de 1920, de modo análogo, os literatos paraenses também se aproximaram do Brasil, aderindo e construindo uma nova identidade nacional. 
1. Uma leitura detalhada do episódio, ao estilo da historiografia romântica do século XIX, em grande medida utilizada para esta síntese, está em Rayol, 1970 (original publicado em 5 volumes entre 1865-1890). Pará uma análise da obra de Rayol e seu contexto político, ver Ricci (1993; 2002).

2. Augusto Meira foi deputado estadual em quatro legislaturas consecutivas entre 1912 e 1930, senador da república entre 1947 e 1951, e deputado federal entre 1951 e 1955, quando se retirou da arena política.

3. Swain (1923: 288). A obra em questão é Römische Geschichte (1854-1856), publicada por Theodor Mommsen em 3 volumes. Sobre o prestígio de Mommsen na historiografia europeia do inicio do século XX, ver Bardt (1903), Guilland (1915) e Fowler (1920).

4. Eliot (1980). Uma análise preciosa desse quadrante da obra de Elliot está em Cook (1979: 341-355).

Sobre o orientalismo de Eliot, ver Jha (1988).

5. Keynes (1919: 33). Cf. também Mantoux (1948: 234-238).

6. Anníbal Amorim (1876-1936), engenheiro e militar do exército brasileiro, em sua viagem ao Pará (1913), muito se impressionou com o trabalho de Palma Muniz no campo da engenharia urbana e na pesquisa histórica, qualificando-o de "profissional laborioso e competentíssimo". Cf. Amorim (1917: 140).

7. Muniz (1922: 18). Sobre o contexto da atuação de Patroni no vintismo português e na imprensa liberal no Pará, vide Coelho (1993) e Figueiredo (2008).
8. O trabalho minucioso de reconstrução da imagem heroica de Grenfell está em Muniz (1926: 8-422).

9. Para uma leitura desse movimento político no contexto da década de 1920, vide Silva (1924) e Brandão (1924). Uma boa revisão da historiografia a respeito está em Mello (2004).

10. Para a leitura da Guerra da Cisplatina na historiografia brasileira e uruguaia do século XX, vide Arreguine (1913);

Brasiliano (1935); Carneiro (1946); Eloy (1970); Castellanos (1974); Quesada (1980).

11. Para uma visão geral do movimento farroupilha, com comentários sobre a atuação de Grenfell, ver Spalding (1939); Freitas (1985); Alves \& Torres (1994).

12. Para uma perspectiva da historiografia militar chilena, ver Valenzuela (1961).

13. Costa (1924: 138). Notar que delenda Carthago (Cartago deve ser destruída), refere-se à sentença com que $M$. Pórcio Catão (234-149 a.C.) terminava suas intervenções no Senado romano, e que acabou adquirindo o sentido de máxima, quando se quer insistir na conveniência de se tomar uma medida drástica. Vide também Haddad (2002), sobre a utilização desse debate nos conflitos anticoloniais na Tunísia do século XX.

14. Estudos sobre a Cartago "púnica" têm longa tradição no século XX; vide, por exemplo, Lapeyre (1942), e Tlatli (1978).

15. O universo ficcional sobre a história de Cartago e seus heróis, especialmente Aníbal, é especialmente extenso. Ver, por exemplo, Osborne (1904); Donauer (1933); Gérard (1935); Bryher (1963); 
Taleb (1973); Leckie (1995); Suarez (2002); Durham (2005).

16. Meira (1906a: 2). Um bom retrato das concepções de história e literatura nesse contexto está em Meira (1906b; 1912).

\section{Referências bibliográficas}

ALVES, Francisco N.; TORRES, Luiz Henrique. 1994. Revolução Farroupilha: história E historiografia. Porto Alegre: Evangraf.

AMORIM, Anníbal. 1917. Viagem ao Brasil: do Rio de Faneiro ao Acre. Rio de Janeiro: Garnier.

ANSART, Pierre. 2004. História e memória dos ressentimentos. In: BRESCIANI, Stella; NAXARA, Márcia (org.). Memória e (res)sentimento. Indagações sobre uma questão sensivel. Campinas: Unicamp.

ARNEIRO, David. 1946. História da Guerra Cisplatina. São Paulo: Companhia Editora Nacional.

ARREGUINE, Víctor. 1913. Estudios históricos: tiempos heroicos y Guerra de la Cisplatina. Montevidéu: Bertani.

BARDT, Carl. 1903. Theodor Mommsen. Berlim: Weidmannsche Buchhandlung.

BARATA, Mário. 1973. Poder e Independência no Grão-Pará, 1820-1823: gênese, estrutura e fatos de um conflito politico. Belém: Conselho Estadual de Cultura.

BLOSSOM, Frederick Augustus. 1915. La composition de Salammbô d'après la correspondance de Flaubert (1857-1862) avec un essai de classement chronologique des letters. Baltimore: Johns Hopkins.
17. Essas teses foram publicadas em comemoração ao centenário da Cabanagem, em 1936. Ver Hurley (1936a; 1936b). Sobre o conjunto dessa obra e seu contexto político, ver Ricci (2007: 309-328).

BOUILLAGUET, Annick. 2000. Proust lecteur de Balzac et Flaubert: l'imitation cryptée. Paris: Honoré Champion.

BRAGA, Theodoro. 1915a. Apostillas de historia do Pará. Belém: Imprensa Official.

1915b. A arte brasílica atravez da ceramica da ilha de Marajó. In: Moura, Ignacio (org.). Annuario de Belém. Belém: Imprensa Official.

1916. Guia do Estado do Pará. Belém: Typ. do Instituto Lauro Sodré.

1917. A arte decorativa entre os índios selvagens da foz do Amazonas. Revista do Instituto Historico e Geographico do Pará, vol. 1, n. 1.

1919. Noções de chorographia do Estado do Pará. Belém: Empreza Graphica Amazônia.

- 1920. História do Pará. Revista do Instituto Histórico e Geographico do Pará, vol. 3, n. 3 .

1931. Historia do Pará: resumo didactico. São Paulo: Melhoramentos.

BRANDÃO, Ulisses. 1924. A confederação do Equador. Recife: IAHGP.

BRASILIANO, Rubio. 1935. O Rio Grande do Sul e a Cisplatina. Porto Alegre: Oficinas Gráficas do Globo. 
BRYHER, Winnifred. 1963. The coin of Carthage. Nova York: Harcourt, Brace \& World.

CASTELLANOS, Alfredo Raúl. 1974. La Cisplatina, la independencia y la república caudillesca, 1820-1838. Montevidéu: Banda Oriental.

CHARDIN, Philippe. 2000. Réceptions créatrices de l'œuvre de Flaubert. Tours: Université François Rabelais.

CLÉMENT, Bruno. 1999. Le lecteur et son modèle: Voltaire, Pascal, Hugo, Shakespeare, Sartre, Flaubert. Paris: Puf.

COELHO, Geraldo Mártires. 1993. Anarquistas, demagogos e dissidentes: a imprensa liberal no Pará de 1822. Belém: Cejup.

COOK, Eleanor. 1979. T. S. Eliot and the Carthaginian Peace. English Literary History, vol. 46, n. 2.

CORDINGLY, David. 2007. Cochrane the dauntless: the life and adventures of Admiral Thomas Cochrane, 1775-1860. Londres: Bloomsbury.

COSTA, Candido. 1900. Duas americas. Lisboa: Bertrand.

1919. Momento historico. Belém: Tavares Cardoso.

1924. Livro do centenário: além da consagração a independência política do Pará. Belém: Guajarina de Francisco Lopes.

DONAUER, Friedrich. 1933. Swords against Carthage. Londres: Longmans.

DURHAM, David Anthony. 2005. Pride of Carthage: a novel of Hannibal. Nova York: Doubleday.

DÜRR, Volker. 2002. Flaubert's Salammbô: the ancient Orient as a political allegory of nineteenth-century France. Nova York: P. Lang.

ELIOT, Thomas Stearns. 1980. The Waste Land. Facsimile and transcript of the original drafts including the annotations of Ezra Pound. Londres: Faber and Faber Limited.

ELOY, Rosa Alonso et al. 1970. La oligarquía oriental en la Cisplatina. Montevidéu: Pueblos Unidos.

FIGUEIREDO, Aldrin Moura de. 2006. Panteão da história, oratório da nação: o simbolismo religioso na construção dos vultos pátrios da Amazônia. In: Neves, Fernando A. de F; Lima, Maria R. P. (org.). Faces da história da Amazônia. Belém: Paka-Tatu. 2008. A memória modernista do tempo do Rei: narrativas das guerras napoleônicas e do Grão-Pará nos tempos do Brasil-Reino, 1808-1931. Revista do Arquivo da Cidade do Rio de Faneiro, vol. 2.

No prelo. Nimuendaju versus Hurley: história intelectual e política indigenista na Amazônia nas primeiras décadas do século XX. Anais do Arquivo Público do Pará.

FLAUBERT, Gustav. 1905. Salammbô. Tradução de João Barreira. $2^{\mathrm{a}}$ ed. Porto: Livraria Chardon. 1990. Lettres d'Orient. Bordeaux: L'Horizon Chimérique. 2001. Voyage en Egypte sur les pas de Flaubert: voyage en Orient de Gustave Flaubert. Présenté par Richard Lebeau; photographies, Michel Le Louarn; dessins, Loustal. Paris: Garde-temps.

FOWLER, W. Warde. 1920. Roman essays and interpretations. Oxford: Clarendon.

FREITAS, Décio et al. 1985. A Revolução Farroupilha: história Eं interpretação. Porto Alegre: Mercado Aberto.

GAGNEBIN, Bernard. 1992. Flaubert et Salammbô: genèse d'un texte. Paris: Puf.

GÉRARD, Francis. 1935. The scarlet beast. Nova York: Longmans.

GUILLAND, Antoine. 1915. Modern Germany $\mathcal{E}$ her historians. Londres: Jarrold \& Sons. 
HADDAD, Mezri. 2002. Non delenda Carthago: Carthage ne sera pas détruite: autopsie de la campagne antitunisienne. Mônaco: Rocher.

HURLEY, Henrique Jorge. 1920. Viagem à aldeia dos Tembés. Revista do Instituto Historico e Geographico do Pará, vol. 3, n. 3 .

1928. Nos sertões do Gurupy.

Belém: Officinas Graphicas do

Instituto Lauro Sodré.

1931a. Amazônia cyclopica. Rio de Janeiro: Castelo Branco.

1931b. Prehistoria americana.

Revista do Instituto Histórico e Geográfico do Pará, vol. 6, n. 6.

1932a. Dialeto Urubú, amerabas da raça tupy do Gurupy. Revista do Instituto Historico e Geographico do Pará, vol. 7 , n. 7.

1932b. Prol cathechese do aborígene brasileiro. $\mathrm{O}$ serviço de proteção aos "índios" do Pará e talvez no Brasil, por sua inefficiencia, é pura ficção. Revista do Instituto Histórico e Geográfico do Pará, vol. 7, n. 7.

1934. Itarãna (pedra falsa): lendas, mitos, itarãnas e "folk-lore" amazônicos. Revista do Instituto Histórico e Geográfico do Pará, vol. 9, n. 9.

1936a. A Cabanagem. Belém: Livraria Clássica.

1936b. Traços cabanos. Belém: Officinas Graphicas do Instituto Lauro Sodré. vol. 1, n. 8 .

JHA, Ashok Kumar. 1988. Oriental influences in T.S. Eliot. Allahabad: Kitab Mahal.

KEYNES, John Maynard. 1919. The economic consequences of the peace. Londres: Macmillan.
LAPEYRE, Gabriel. 1942. Carthage punique (814-146 avant f.-C.) avec 2 cartes, 7 figures et 34 gravures hors texte. Paris: Payot.

LECKIE, Ross. 1995. Hannibal. Edimburgo: Canongate Books.

LOBO, Luiz; MUNIZ, João de Palma; CAMPOS, Américo. 1922. Apresentação. Revista do IHGP, vol. 6, n. 4.

LORETO, Luigi. 2007. La grande strategia di Roma nell'età della prima guerra punica (ca. 273-ca. 229 a.C.): l'inizio di un paradosso. Nápoles: Jovene.

LORINSZKY, Ildiko. 2002. L'Orient de Flaubert: des écrits de jeunesse à Salammbô: la construction d'un imaginaire mythique. Paris: Harmattan.

MANTOUX, Etienne. 1948. The Carthaginian Peace, or the economic consequences of Mr. Keynes. Economica, New Series, vol. 15, n. 59.

MEIRA, Augusto. 1906a. Flaubert em Portugal. O Luzitano. Belém, 18 nov. 1906b. Eis o livro: estudos de philosofia, religão e historia. Belém: Typ. Pinto Barbosa.

- 1908. Pirina. Paris: L. Brou. 1912. Discurso. Pará: Typ. do Instituto Lauro Sodré. 1913. Direito e arbítrio. Pará: Typ. da Livraria Escolar.

MELLO, Evaldo Cabral de. 2004. A outra independência: o federalismo pernambucano de 1817 a 1824. São Paulo: 34.

MUNIZ, João de Palma. 1922. Adhesão do Grão-Pará à Independência. Revista do Instituto Histórico e Geográfico do Pará, vol. 6, n. 4.

MUNIZ, João de Palma. 1926. Grenfell na história do Pará, 1823-1824. Annaes da Biblioteca e Archivo Público, vol. 10. 
OSBORNE, Duffield. 1904. The lion's brood. Nova York: Doubleday, Page \& Co.

QUESADA, Efraín. 1980. La emancipación oriental: antología gráfica y literaria. Montevidéu: Ediciones de la Plaza.

RAYOL, Domingos Antonio. 1970. Motins políticos ou história dos principais acontecimentos políticos da provincia do Pará desde o ano de 1821 até 1835. 3 vols. Belém: Universidade Federal do Pará.

REID, Martine. 1995. Flaubert correspondent. Paris: Sedes.

RICCI, Magda. 1993. História amotinada: memórias da Cabanagem. Cadernos do $\mathrm{CFCH}$, vol. 12, n. 1-2.

2002. O Império lê a Colônia: um barão e a história da civilização na Amazônia. In: BEZERRA NETO, José Maia; GUZMÁN, Décio. (org.). Terra matura: historiografia e história social da Amazônia. Belém: Paka-Tatu.

2007. Folclore, literatura e história: a trajetória de Henrique Jorge Hurley. In: FONTES, Edilza; BEZERRA NETO, José Maia. (org.). Diálogos entre história, literatura e memória. Belém: Paka-Tatu.

ROCHA, Mecenas. 1907. Ruinas. Porto: Chardron. 1908. Heras. Porto: Typ. Moderna.
SILVA, Manoel Cicero Peregrino da. 1924. Pernambuco e a Confederação do Equador: conferencia realizada no Instituto Historico e Geographico Brasileiro a 2 de julho de 1924. Rio de Janeiro: Imprensa Nacional.

SPALDING, Walter. 1939. A Revolução Farroupilha (historia popular do grande decenio seguido das "efemérides" principais de 1835-1845, fartamente documentadas). São Paulo: Companhia Editora Nacional.

SUAREZ, Anastassia. 2002. Masinisa: León del Atlas: novela histórica. Bucaramanga, Colômbia: Sic.

SWAIN, J. Ward. 1923. What is history? The Fournal of Philosophy, vol. 20, n. 11.

TALEB, Mirza. Hannibal, man of destiny. Boston: Branden Press.

TLATLI, Salah-Eddine. 1978. La Carthage punique: étude urbaine: la ville, ses fonctions, son rayonnement. Paris: J. Maisonneuve.

VALE, Brian. 2004. The audacious Admiral Cochrane: the true life of a naval legend. Londres: Conway Maritime.

. 2008. Cochrane in the Pacific: fortune and freedom in Spanish America. Londres: I. B. Tauris.

VALENZUELA, Ricardo. 1961. Cochrane, marino y libertador, 1775-1860. Valparaíso: Marina de Chile.

\section{Resumo}

Este artigo analisa os debates historiográficos travados em 1923 por ocasião das comemorações da adesão do Pará à Independência do Brasil. Para isso, retoma os usos, pela intelectualidade paraense da época, dos mitos políticos da Antiguidade clássica, como as Guerras Púnicas, e de uma série de conceitos veiculados internacionalmente nos anos de 1910 e 1920, em obras políticas e literárias: "paz cartaginesa" em Keynes (1919), "terra desolada" em Elliot (1922) e ainda as imagens de Cartago na obra de Flaubert (1862). Mais do que 
um exercício de erudição, esse repertório analítico significou um longo e atribulado processo de construção da "moderna" identidade nacional na Amazônia.

Palavras-chave: Independência, efeméride, modernismo, Antiguidade clássica

\section{Abstract}

This article analyzes the historiographic debates held in 1923 during the celebrations of the joining of Pará State to the Independence of Brazil. To do so, it examines the uses by local intellectuals of political myths of Classic Antiquity, as the Punic Wars, and of a series of concepts transmitted internationally in the 1910's and 1920's in political and literary works, as Keynes' "Carthaginian peace" (1919), Elliot's "West Land" (1922) and Flaubert's images of Carthage (1862). More than an erudite exercise, this analytical repertoire expressed the long and difficult process of building a "modern" national identity in Brazilian Amazon.

Key words: Independence, celebration, modernism, Classic Antiquity

\section{Résumé}

Cet article analyse les débats historiographiques suscités en 1923 lors des commémorations de l'adhésion de l'état du Pará à l'indépendance du Brésil. A cet effet, il contemple l'usage, par les intellectuels du Para à l'époque, des mythes politiques de l'Antiquité, tels les Guerres Puniques, ainsi que d'une série de concepts véhiculés internationalement dans les années 1910 et 1920 par des oeuvres politiques et littéraires: la "paix carthaginoise" de Keynes (1919), "la terre désolée" de T. S. Elliot (1922) et l'évocation de Carthage dans l'oeuvre de Flaubert (1862). Plus qu'un exercice d'érudition, ce répertoire analytique s'inscrit dans un long et difficile processus de construction d'une identité nationale "moderne" en Amazonie.

Mots-clés: Indépendance, célébration, modernisme, Antiquité Classique 